\title{
Exploring factors of the sustainable supply chain in the post-COVID-19 pandemic: SWARA approach
}

\author{
Khizar Hayat ${ }^{1}\left[\right.$ ] Zhu JianJun $^{1} \cdot$ Sharafat Ali $^{1,2} \cdot$ Muhammad Adeel Khan $^{3}$
}

Received: 29 May 2021 / Accepted: 2 October 2021 / Published online: 16 October 2021

(c) The Author(s), under exclusive licence to Springer-Verlag GmbH Germany, part of Springer Nature 2021

\begin{abstract}
The present research aimed to provide a mechanism for enhancing sustainable supply chain survivability (SSCS) during and after the COVID-19 outbreak. Logistical and manufacturing operations have been restricted due to the severe lockdown, which significantly impacts the demand and supply of various items. COVID-19 has a massive effect on a multitude of units of various sectors. This research emphasized the important elements that must be considered to adapt the sustainable supply chain (SSC) practices. As a result, businesses are now attempting to improve the system for SSC. The stepwise weight assessment ratio analysis (SWARA) approach is used in this research to classify dynamic aspects for improving SSC survival in an epidemic condition. The results reveal that the viability of the supply chain network is the essential criteria for managing the relationships of suppliers and buyers and maximizing SSCS during and after COVID-19. This research will help businesses, manufacturers, and other stakeholders to concentrate on the described factors to achieve a brighter environment.
\end{abstract}

Keywords Sustainable supply chains $\cdot$ Survivability $\cdot$ Post-COVID-19 $\cdot$ Viability $\cdot$ Digital data-driven supply chains . Buyer-supplier relationship

\section{Introduction}

Demand-supply distraction is influencing global and local supply chains worldwide due to the COVID-19 outbreak (Thiagarajan 2021). Consequent to government restrictions such as lockdowns, quarantine restrictions, and border controls due to pandemic outbreaks worldwide, international trade reduced from 12 to 33\% (WTO 2020; Araz et al. 2020; Guan et al. 2020). One thousand fortune companies have been influenced by COVID-19 (Mckinsey 2020; Fortune 2020). Although many risk factors are overwhelming, resiliency in the supply systems can be established quickly

Responsible Editor: Eyup Dogan

Khizar Hayat

khizarhayat@nuaa.edu.cn

1 College of Economics and Management, Nanjing University of Aeronautics and Astronautics, Nanjing 211106, Jiangsu, People's Republic of China

2 Department of Economics, Government Graduate College Kot Sultan, Kot Sultan 31650, Layyah, Punjab, Pakistan

3 Department of Business Administration, Bahauddin Zakariya University, Multan, Pakistan
(Ivanov 2020). However, empirical studies on supply chain robustness and resilience would provide deeper insights into how the affected and likely to be affected would encounter risks posed by COVID-19. In addition, such studies would also provide guidelines to implement preservative strategies to reduce the negative impacts of the pandemic on the supply chain (Dolgui et al. 2020). Similarly, Mckinsey 2020 emphasizes supply chain managers' efforts to execute risk and supply chain resilience. It encourages experts to do an empirical study on how suppliers cope with post-COVID-19 issues for a sustainable supply chain (SSC).

Coordination of suppliers is critical for building customer relationships to have sustainable outcomes (Badraoui et al. 2020; Reuter et al. 2010; Alghababsheh and Gallear 2020). Global sustainability encourages firms to redesign and reform economic, social, and environmental concerns for maintaining the buyer-supplier relationship by mutual coordination (Ni and Sun 2018). Due to the rise of the coronavirus, a life-threatening environment hovering over the globe putting enormous pressure on businesses' stakeholders, governments, and policymakers to maintain their supply chains due to social, environmental, and economic factors (Cohen 2020; Sarkis et al. 2020). As the COVID-19 pandemic has put enormous disruptions on the survivability of 
the supply chains management all over the globe, it makes it imperative to identify, assess, and prioritize the factors affecting SSC. Like the rest of the world, Pakistan's economy has also faced a COVID-19 pandemic and its negative impacts. COVID-19 pandemic has also affected the SSC of fast-moving consumer goods (FMCGs). The present study develops a framework to identify, assess, and prioritize factors disrupting FMCGs supply chains using the stepwise assessment ratio analysis (SWARA) method. The study's findings would provide a deeper understanding of SSC survivability in COVID-19 and post-COVID scenarios.

\section{Previous research and motivation}

Various studies in the literature focus on the analysis of supply chain management (SCM) and its factors. Seuring and Müller (2008) developed a conceptual framework for an SSC using a review approach. Based on SSC growth, Winter and Knemeyer (2013) carried out a thorough analysis of growth in three areas (operations, social, and environmental management). Ashby et al. (2012) tried to trace the evolution of long-term supply chain systems, processes, and interactions. Carter and Easton (2011) and Rajeev et al. (2017) aimed to discover the evolution of SSCs and provide recommendations for future study across all sectors and geographies. Some of the findings from the literature reviews on SSCs have been presented using a specific phenomenological approach, such as dynamic capacity (Beske and Seuring 2014) and decision philosophy (Tidy et al. 2016). In the comprehensive explanation by Seuring (2013) and Brandenburg et al. (2014), so many applications of comparative features to a forwardsupply chain for sustainability have been mentioned; Reuter et al. (2010) expanded by highlighting the efficacy of business analytics means of achieving SSC. Barbosa-Póvoa et al. (2018) also offered literature evaluations on the SSC from 2006 onwards. None of the research was solely focused on SSC and buyer-supplier relationship evolution in the FMSGs particularly.

\section{Purpose and contribution}

However, the development of conceptual theories to illustrate the factors for SSC and buyer-supplier relationship with environmental, social, and economic performance in the context of post-COVID-19 did not explore. Thus, the most important considerations on which supply chains can concentrate to achieve survivability during pandemics remains unanswered. The following empirical questions must be addressed by qualitative research. Which variable plays a vital role in improving the SSCS in post-COVID-19 scenarios? During COVID-19 outbreaks, how is the buyer-supplier partnership managed? What do supply chains rely on to survive in the post-COVID-19 for the long term? Comprehensively, the study intends to look at and analyze the influential elements for SSCS during post-COVID-19. Thus, a thorough analysis is carried out, and the following research priorities are set in. In today's competitive business environment, a reliable and SSC is essential to business performance. However, natural (e.g., coronavirus) or man-made crises frequently interrupt the sustainable supply chain (Sarkis et al. 2020).

FMCGs and a portion of the resilient food and healthcare supply chain are among the key elements. A manufacturer must evaluate supply chain interruptions induced by a disaster such as COVID-19 that may occur at the retailer and supplier end to maintain an SSC. Most of the previous studies emphasized interruptions at the supplier or retailer level (e.g., Konstantaras et al. 2019; Paul et al. 2018). But this study adds to the existing research by demonstrating the key factors contributing to an SSC and the survival of the buyer-supplier relationship in the wake of the post-COVID-19. In real-world situations, decision-makers must examine the supply chain's social, environmental, and economic sustainability since these components increase the supply chain's capacity to satisfy consumer demand (Mehranfar et al. 2019; Nezhadroshan et al. 2020). So, such a significant aspect is needed to assist supply chain managers in making decisions for an SSC under postCOVID-19 circumstances. The previous work examined supply chain challenges, but there has been no thorough analysis of the required significant factors for increasing SSC survival post-COVID-19. As a result, this study fills in the gaps and examines the elements to provide firms unique insight into how to rebuild their SSCs to survive in pre-and post-COVID-19 circumstances.

This research is helpful to understand the factors that contribute to SSCs during the post-COVID-19 pandemic. This study adds the knowledge of the core considerations that must be weighed to sustain an efficient buyer-supplier relationship and increase the SSC. Our study subsidizes the academic literature and delivers appropriate insights to companies as well. Moreover, the findings shed light on the effects of SSC execution on both supply chain resilience and robustness.

"Literature review" consists of the literature review and theoretical framework used in this study. "Proposed research framework" discusses the research framework; "Research methodology" discusses the research methodology. "Results and discussion" highlights the results and discusses the findings and "Conclusion and implications" presents the conclusion and implications.

\section{Literature review}

\section{Sustainable development}

The fundamental objective of sustainable development is to increase flexibility and resilience (Barrow 2018). 
Sustainable innovation can help businesses become more competitive (Agrawal et al. 2021). Schoenmaker (2019) and Ikram et al. (2020a, b) illustrate the environmental, economic, and social challenges of sustainable development and rank them as follows: environmental challenges are essential for a livable planet; next, social challenges are important due to a well-connected society that can organize production and consumption to bring prosperity; and finally, economic challenges are the most difficult to overcome. The United Nations Convention (1972) on the Human Environment was the one to promote sustainability. Following the Brundtland report in 1987, there was a surge in worldwide attention to sustainability (Klewitz and Hansen 2014). According to the World Commission on Environment and Development (WCED), sustainability is defined as "meeting the requirements of the present, without affecting future generations' ability to fulfill their particular goals" (WCED 1987).

Sustainable development comprises teaching and learning about sustainability for stakeholders and promoting principles and practices that are compatible with the organization's goals. Sustainable development demands comprehensive risk assessment, vulnerability monitoring and evaluation, and the identification of constraints and opportunities to minimize issues and improve adaptability. This research highlighted key indicators that might help them to restructure their supply chain for sustainability and better buyer-supplier relationships.

\section{Factors for sustainable supply chains}

Organizations are moving to a demand-driven paradigm for handling their supply chains in the pandemic (Chi et al. 2020; Choi and Guo 2020). The interaction of supply chain and environmental growth is the basis of SSC. For managing their relations with distributors, environmental, economic, and social concerns play an imperative role (Dubey et al. 2017; Hayat et al. 2020). COVID-19 has put a lot of stress on organizations offering both tangible and intangible resources, so they are using new types of supply chains to do so. To meet demand and supply, the firms consider outsourcing middlemen and depend on the supply chain system's association with multiple single-level suppliers (Wilhelm et al. 2016). Global supply chains use both traditional and non-digital modes to expand their presence and remain competitive in the industry (Araz et al. 2020). The supply chain's controlled inventory gives the distributor access to actual inventory data, forecasting, and order specifics, which helps the upstream distributor (Prince et al. 2019). Additional platforms, associations, value-adding, co-creation, optimization techniques of distribution and pickup options, omnichannel supply chains, balancing management capacity, order fulfillment, embracing digital applications, and crowd and capital management are all areas where the supply chains are focused (Mckinsey 2020). Studies show that a firm's organizational structure is based on teamwork when it comes to knowledge exchange. Because of the volatile situation, the supply chains have been encouraged to work with various collaborators to minimize ambiguity and reduce risk (Li and Jiang 2019; Madsen and Petermans 2020; Hughes et al. 2019).

\section{Disruptions on sustainable supply chains}

Firms face a variety of risks and threats because of their supply chain environments (Chapman et al. 2002; Peck 2005; Svensson 2004). Disruptions due to the variety of crises (financial, economic, social, ecological, and political) have raised researchers' focus to the need of researching supply chain robustness and resilience. Several pieces of research on companies' reactions to risks through dynamic adaptation to conditions have explored SSC robustness and stability (Dolgui et al. 2020; Pettit et al. 2019; Scholten et al. 2019). In a difficult era, firm survival and expansion have been a serious subject of study in the wake of the COVID-19 epidemic (Ivanov 2020).

The supply chain's efficiency has improved due to the collaboration, reducing costs, and improving profitability. The bullwhip effect in supply chains can be reduced by retailers and suppliers working together (Dolgui et al. 2020). The supply chains come in various shapes and sizes, but they all help alleviate the distress of the affected people. Both physical and intellectual assets are widely shared, and these resources and knowledge exchange are critical for successful communication between suppliers and buyers (Pankowska 2019; Ikram et al. 2021). Supply chain exposure to disruptions has been examined in previous research studies in the physical aspect, uncertainty considerations, and conceptual network analysis (Ivanov et al. 2010; Pavlov et al. 2019; Li and Zobel 2020). Its conservation focus and environment orientation calculate the longevity of a system. The feasibility of supply chains combines efficiency and durability and adds durability to the process (Ivanov and Dolgui 2020). From the available literature, essential elements for improving the buyer-supplier relationships and survival of SSCs are created.

\section{Sustainable supply chain and post-COVID-19}

In supply chain operations, broad socio-political forces have always played an imperative role, whether from tariffs on goods or new norms related to safety practices or regulations on technological practices (Handfield et al. 2020). Consequently, supply chain processes will be transformed postCOVID-19, but will these transformations stay in place? Data-driven recognition is going to be a significant change (Scharmer 2020). This activity entails working together to 
address issues and then modifying action in addition to the COVID-19 dilemma. Companies must change their behavior as processes, particularly market and government legal structures, begin to collapse. Similar expression changes can help with long-term sustainability.

During and after the crisis, organizations and their supply chains will demand more timely data; they will integrate decision-making and establish new programs and initiatives in reaction to the crisis. This organizational capability can help people think more about sustainability when environmental and social problems happen, but their timing and magnitude will be unpredictable. Centralized networks are more likely to be strong and resilient than global supply networks, as seen by this issue (Nandi et al. 2021; Handfield et al. 2020; Ikram et al. 2019). Localization is also critical for the ecological supply chain's long-term viability (Holmstr€om, J. and Gutowski, T. 2017). Local manufacturing can offer quick responses to local demands while using less energy and resources.

While this situation offers chances for long-term sustainability, it also has the potential to frustrate. Although uncertainty and issues persist, we can see a change to SSC arising from this situation. Supply chain resilience is supported by sustainability strategies and practices, such as assuring ecological functions are preserved, enabling more sustainable "buy local" behaviors, and promoting public confidence. The crisis provides a revolutionary opportunity because it allows us to use sustainability to minimize risk and develop resilience.

Researches have investigated supply chain challenges, restrictions, channels, sharing of knowledge, convergence, and supplier engagement (Marques 2019; Roy et al. 2020; Liu and Lee 2018; Nazam et al. 2020); coordination (Wankmüller and Reiner 2020); order fulfillment and delivery supply chains (Ishfaq and Raja 2018); strength and longevity in provider relationships (Touboulic et al. 2014); SCM competition (Tidy et al. 2016; Sauer and Seuring 2017; Patel and Desai 2019); model growth in SCM (Brandenburg et al. 2019) as well as stability and buyer-supplier relationships (Kumar and Rahman 2016).

The existing studies have examined supply chain challenges. Still, there has been no systematic analysis of the requisite significant factors for improving SSCs during pandemics, specifically in the post-COVID-19 context. As a result, this research fills in the gaps. It examines the drivers to give additional insights to supply chains about reinventing their sustainability of supply chains to succeed during and post-COVID-19 scenarios.

The research assists in identifying conditions that contribute to the long-term viability of SSCs and the handling of buyer-supplier relationships. The study guides companies, retailers, government agencies, and professionals about handling their supply chains to meet society's social and economic needs while not losing business in the epidemic. For determining the significant factors to survive in a COVID-19 scenario, this research involves defining variables to design and operate SSCs for FMCGs companies in the unpredictable world of an epidemic (coronavirus) as a distinctive character.

It sheds light on the feasibility and resiliency of supply chains. It can prompt them to modify their current tactics to improve their resiliency in both pre-and post-pandemic scenarios. While progress is being made in environmental and social sustainability, it is slow, irregular, and myopic, and it is easy to fall into unsustainable practices. Therefore, it is important that we critically investigate and demonstrate the factors for SSCs and buyer-supplier strong connection.

\section{Proposed research framework}

To accomplish the research goals, the structure involves a three-step mechanism. In the first step, a comprehensive literature review is used to identify the variables needed to improve SSCS and fair relations between suppliers and buyers in the COVID-19 epidemic. The confirmation of elements and exploration using the SWARA tool for weight calculation is included in the second stage. The critical reasons for handling SSC and supplier relationships are defined and addressed after the weights have been determined in the third stage. Figure 1 demonstrates the anticipated study configuration.

\section{Research method}

The procedure is divided into the following five stages: (I) defining study aim and intentions; (II) keyword classification; (III) database selection; (IV) variety of research papers, and $(\mathrm{V})$ analysis of data. The questions are presented for SSCs, and the buyer-supplier partnership, followed by a database including "Web of Science" (WoS) and "Scopus." The phrases supply chain and sustainability of supply chain, supplier relationship or resiliency, or supplier's network, the configuration of supply chain and governance of supply chain, the viability of supply chain network and collaboration of supply chain are used to finding the keywords. These terms were used to find out the related literature merely. Because to search the related paper in bulk and then screened the most relevant, the exact phrases used for the main criterion in the study have been considered. The terms that have been used, evaluated by a panel of experts in the supply chain, sustainability, and resilience fields to help ensure completeness and accuracy. When it was confirmed, the terms are suitable and valid for exploring the factors for SSC and buyer-supplier relationship, then moved to next for literature searching. These terms were used to 


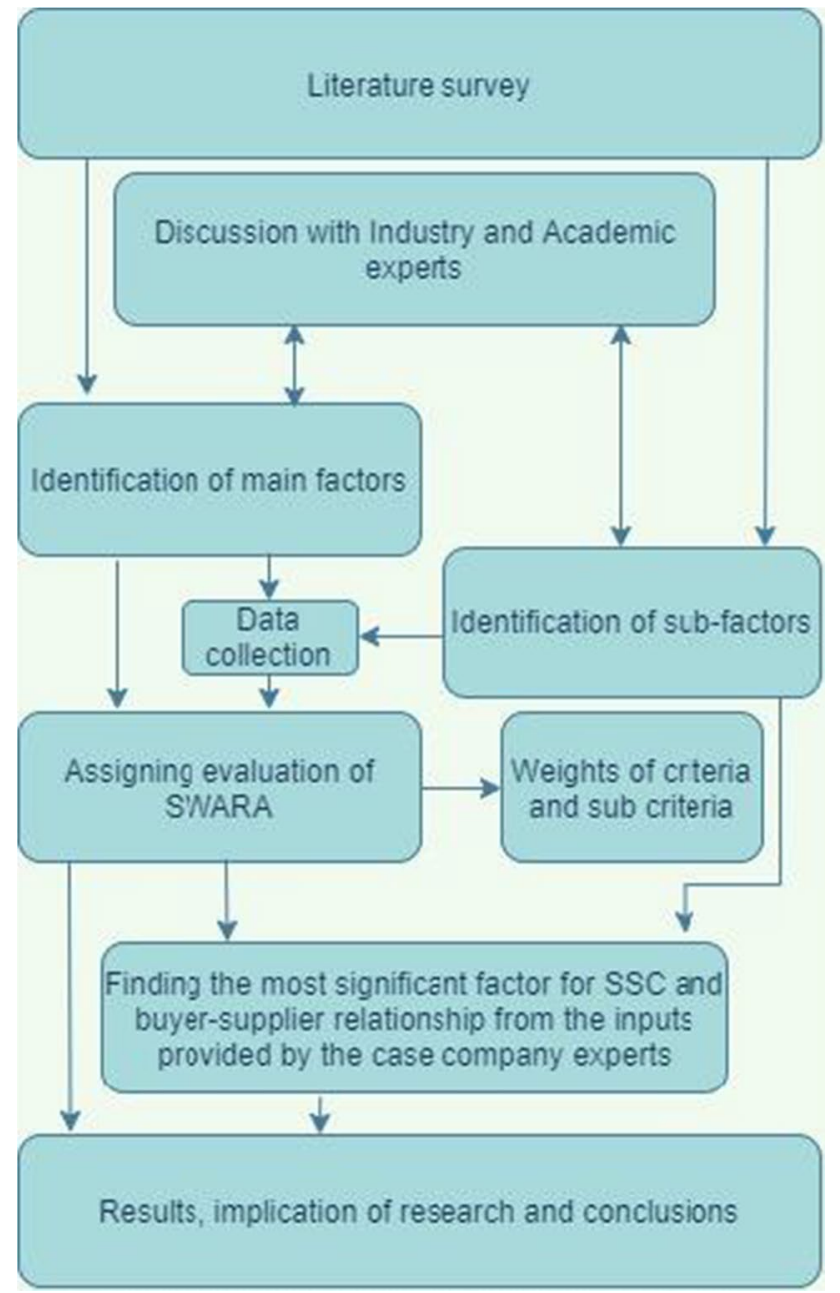

Fig. 1 The research framework

take the elements for data collection from experts through questionnaires. Thus, the terms must appear in the abstract, names, and keywords - the paper considered between 2012 to 2021 in the study. The first search found 378 papers from the web of science and 640 Scopus papers. After removing copied from the papers, 910 research papers according to the research questions are listed. Conference papers, presentations, and working papers did not include, so only published in journals were included for review.

After excluding the unrelated pieces, a total of 201 research papers are listed. After reviewing the significant and targeted factors for increasing the sustainability of the supply chain and buyer-supplier relationship, these papers were chosen. The elements are categorized according to the triple bottom line aspects of sustainability by following the method of (Thakur and Mangla 2019), including environmental, economic, social, and considerations. After reviewing the abstracts of the articles, a total of 39 papers were chosen. Factors for improving SSC and buyer-supplier relationships are built from the listed articles. Each professional must carefully review the data sheet with the questionnaire and assess each factor (Appendix A). In "Propose framework application," expert information is given.

Experts evaluate these elements based on six key parameters - criteria 1 (Crt1): supply chain performance in uncertain conditions; criteria 2 (Crt2): configuration of supply chain (CSC); criteria 3 (Crt3): governance of supply chain (GSC); criteria 4 (Crt4): viability of network of the supply chain (VSC); criteria 5 (Crt5): collaborations of the supply chain; criteria (6) (Crt6) digital data-driven of the supply chain. There are sub-criteria for each criterion. All these factors were not used in a single study to evaluate the relationship between sustainable supply chain and buyer-supplier relationship. After screening the bulk literature, various factors from diverse studies were selected. This research combines all the elements in assessment to determine the influential factor for SSC and buyer-supplier relationship. In normal conditions, the researchers used some aspects in the supply chain with moderation and mediation for numerous purposes. Still, all these factors in one study are rarely used for an SSC. Negri et al. (2021) state that the same factors but different situations show different relationships and outcomes. We cannot compare normal and uncertain conditions results because all given elements were not used in any analysis. So, these factors were not used to aim for SSC and buyer-supplier relationship in the normal condition but for other purposes. In short, the same factors but in various conditions show the different connections.

Table 1 shows the final representation of the primary and sub-criteria. This has tried to engage with the infected supply chains because of coronavirus outbreaks.

\section{Propose framework application}

The research's primary focus is building SSCs and maintaining buyer-supplier relationships in the post-COVID situation. The selected variables are almost a complete set because these are the essential elements and influential factors in the supply chain. The researchers recommended the variables chosen in supply chain-related studies. After finalizing the aspects, the experts and senior researchers reviewed the sheet and suggested adding the elements of collaboration of the supply chain, which was added in the final selection. After the suitable suggestion and approval, we reviewed the factors list with experts. The factors are imperative for an SSC and buyer-supplier relationship and forward to data collection. The study has taken 18 experts with the same expertise, skills, and resources for data collection.

The supply chain must check in the changing world and, based on the results to take constructive measures for better outcomes. Three managers from the manufacturing and procurement divisions are also among the specialists. The 


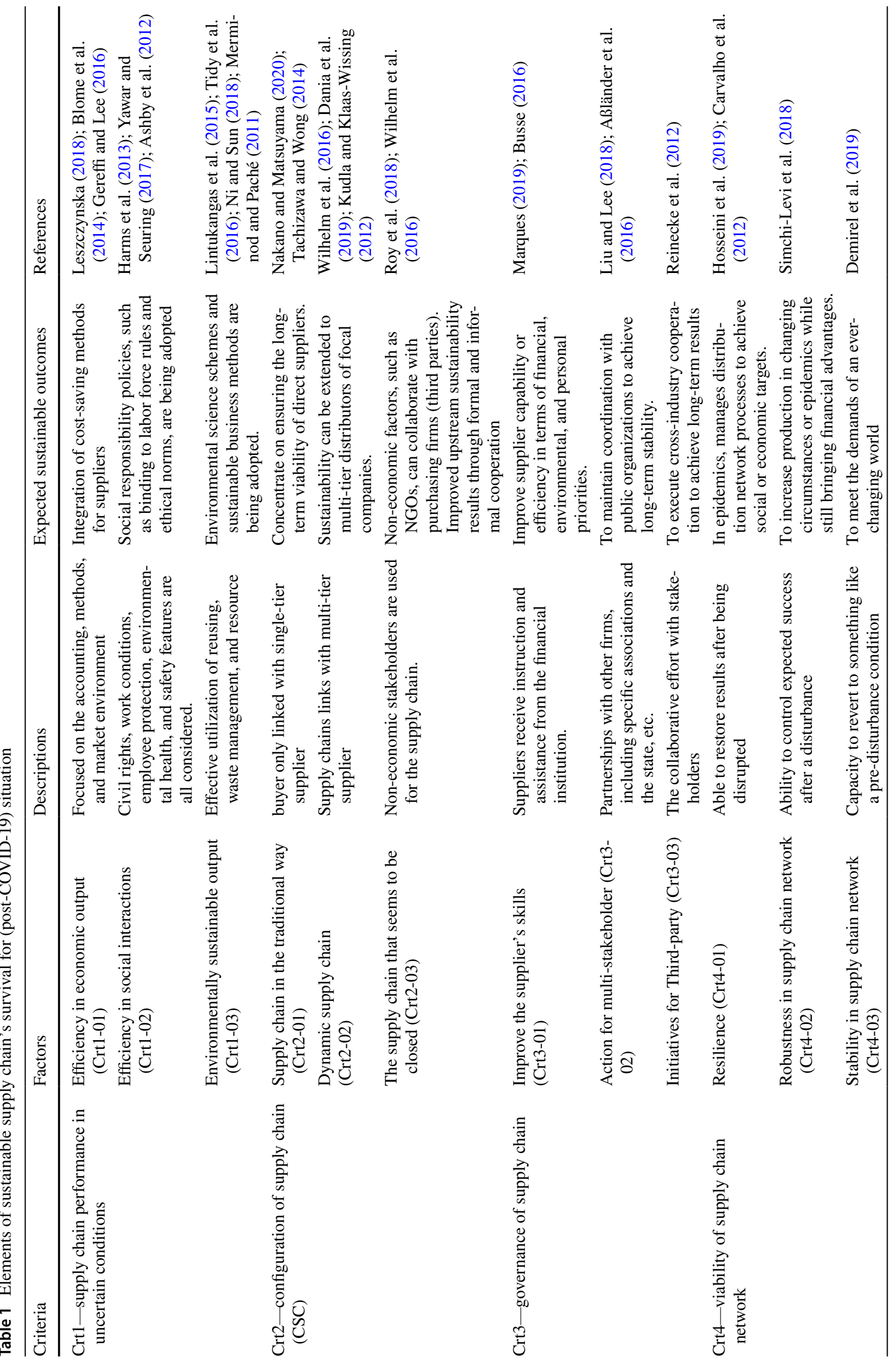




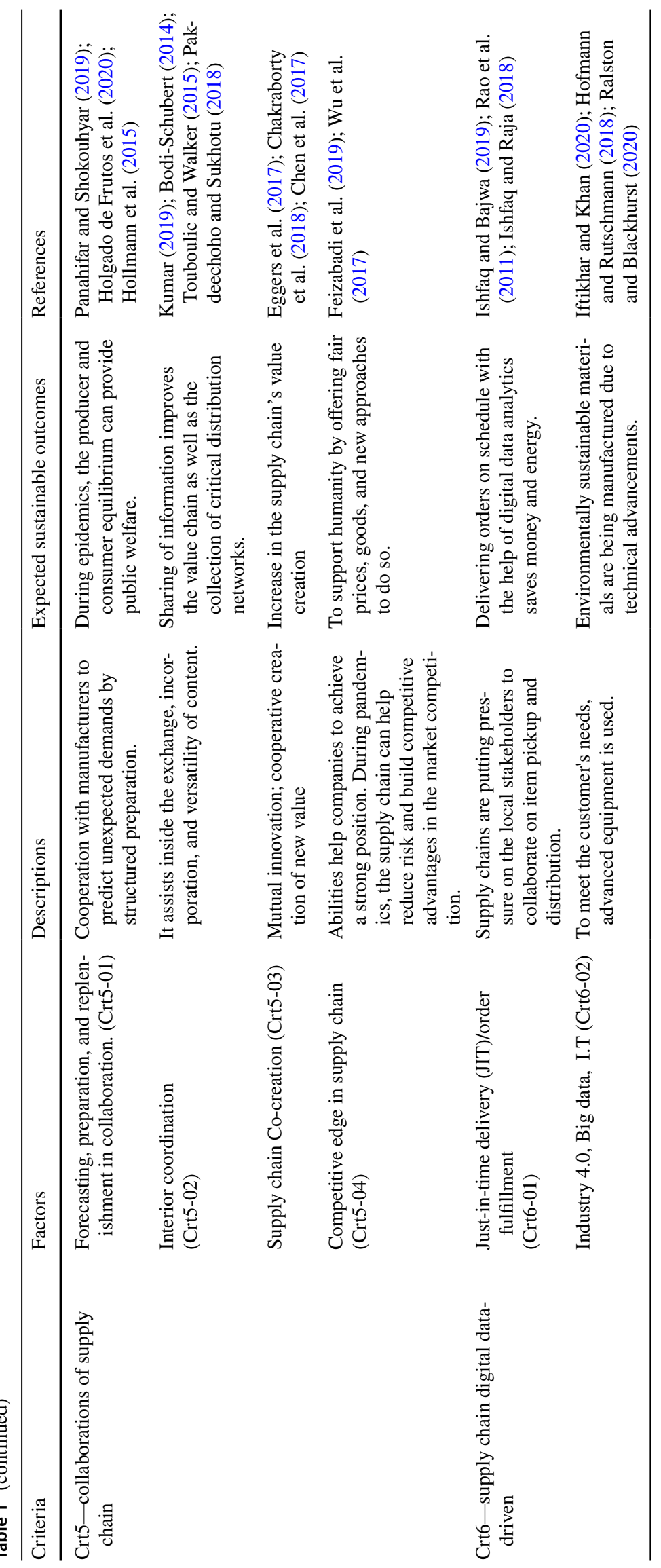


two managers from the sales department have been tasked with considering demand and sales dynamism. Manufacturers, retailers, and suppliers are also considered specialists in understanding the downstream supply chain. Two shipment executives are comprised in the advisory group for logistical input. For more than 10 years, the supply chains have been working with the manufacturers, dealers, and sellers in the expert panel. The selected supply chain practitioners manage demand and supply, procurement, manufacturing, client associations, order fulfillment, shipping, logistics, and sales. The experts' expertise ranges from 10 to 15 years. The experts are mailed the extensive details about all the elements and the questionnaire for their answers (Appendix Table 6). The factors and sources for measuring sustainability are given in Table 1.

\section{Research methodology}

The analysis used the advanced MCDM approach SWARA (stepwise weight assessment ratio analysis). Because MCDM is the hub of decision-making approaches (Ikram et al. 2020a, b). The SWARA approach calculates the weights of variables to help the SSC built on its sustainable enactment. The SWARA approach assists decisionmakers in decreasing ambiguity and biases. It is the most appropriate tool for making high-level decisions (Zavadskas et al. 2018). The other related studies include (Singh and Modgil 2020; Prajapati et al. 2019a, b; Karuppiah et al. 2021; Gupta and Soni 2021; Agarwal et al. 2020), and many other researchers used the SWARA approach for the supply chain area. Experts play a critical part in the method's measurement and calculation of weights and measures. An expert evaluates parameters based on their expertise, information, and experience. The essential component of this approach is the ability to estimate experts' opinions on the significance ratio of the criterion for weight determination. The ability to exclude irrelevant parameters and factors is the key benefit of this approach. When experts compare the parameters, they may conclude the standards are irrelevant in the established model of research intention due to the significant difference (Zolfani and Saparauskas 2013). It allows business practitioners to pick up their main concerns based on current environmental and economic conditions (Gandhi et al. 2016). Thus, in the context of COVID-19, the SWARA technique will help analyze the factors. As a result, making it easier for decision-makers to use. SWARA is the most appropriate method for this research because this study aims to identify factors that will improve the SSC in a pandemic situation. The following section discusses this method in detail.
SWARA method (stepwise weight assessment ratio analysis)

The SWARA approach assists in determining the factors that contribute to long-term supply chain sustainability (Karabasevic et al. 2015). According to Wang et al. (2019), this approach computes the relative/comparative weight coefficients that provide accurate outcomes in the analysis for a better decision. SWARA has significant capabilities over other weighting tools; it can estimate experts' opinions about the importance ratio of criteria in the weighting process. SWARA is useful for managing and collecting data from experts. It is transparent, and analysts can conveniently collaborate. An advantage of this approach is that it calculates issue preferences depending on company policy. Consequently, no need to rank the parameters first. SWARA gives stakeholders the ability to make choices depending on various scenarios and evaluate parameters based on their specific priorities and objectives. This approach brings professional input into the creation of such critical projects. As a result, the SWARA approach has been considered a key instrument in the decision-making and policy-making processes at the highest ranks of businesses and organizations. Professionals are requested to rate each weight's superiority and rank it in order of choice based on their understanding, skills, and experience. On a 9-point scale, the most critical parameter is rated first, and the last imperative benchmark is ranked nine. This approach has been used to make decisions in various fields, including sustainability, green provider, site, solar plant, service quality, car, and several others (Prajapati et al. 2019a, b; Vafaeipour et al. 2014).

Compared to other MCDM approaches, SWARA is a simple and less time-consuming method (Singh and Modgil 2020). SWARA's judgment is based on the expertise and experience of experts. This technique considers that one quality is more or less important than others (Keršuliene et al. 2010). This approach determines the importance of qualities in making judgments. To obtain the relative weights of the criterion, Keršuliene et al. 2010 presented five stages. As an addition to the traditional SWARA approach, step 6 is included. Following the method of Prajapati et al. (2019a, b), the flowchart in Fig. 2 depicts the six-step SWARA technique procedure.

The procedures for calculating weights are shown below.

Step 1. Organize requirements according to experts' recommendations. According to expert opinion, the criteria are arranged in descending order.

Step 2. Begin with the second criteria, the participant indicates the relative importance of criterion $j$ to the initial $(j$ 1) criterion, and so on for each criterion. Kersuliene et al. 2010 named this ratio the comparative importance of the average value, $S j$. Determine the proportional weighting 


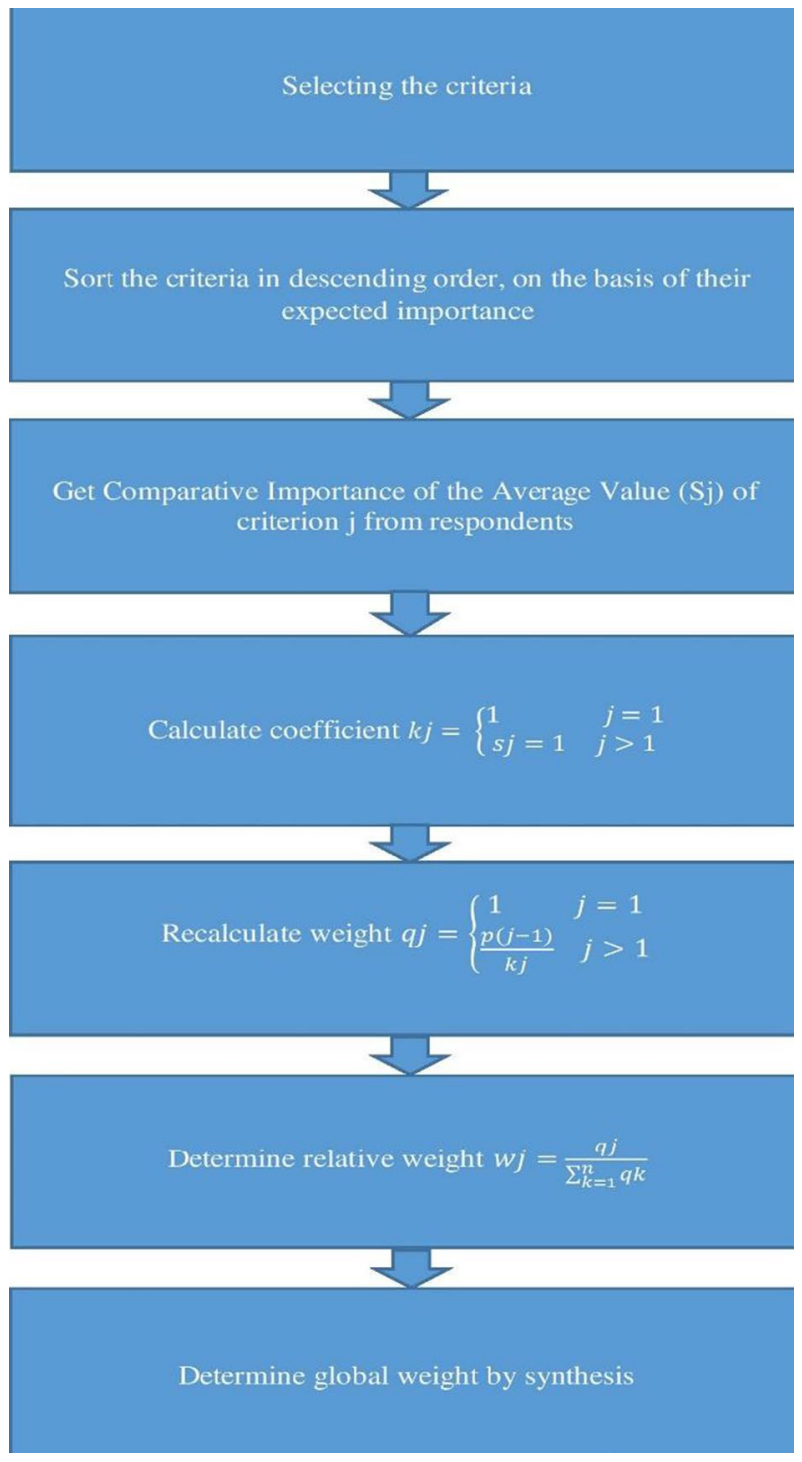

Fig. 2 Framework for SWARA steps

of parameters. Experts demonstrate the related significance of the $j$ th criterion under the previous $(j 1)$ criterion by comparing the importance of the average value $(s j)$ ratio from the second criterion forward.

Step 3. Computation of co-efficient $k j$ :

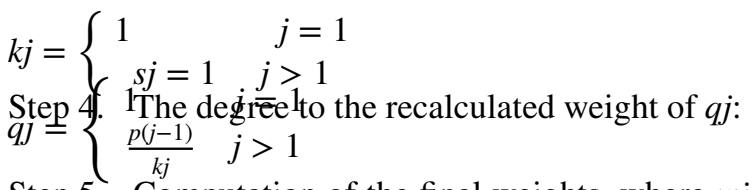

Step 5. Computation of the final weights, where $w j$ is the relative weight of the wth criterion and $n$ is the number $w j=\frac{\text { of megisures: }}{\sum_{k=1}^{n} q k}$

Step $6 .{ }^{k} \overline{\bar{S}}$ ynthesis
The main category's $w j$ value is calculated by their respective sub-category $w j$ value, generating a new global $w j$ value for every single part. This reflects the impact of the primary category on its sub-category. Synthesis is another name for this process (Keršuliene et al. 2010). Each criterion will be given the same amount of weight as the number of experts. To achieve a composite weight for each criterion, the judgment is combined with the help of the geometric mean (Keršuliene et al. 2010). Based on these composite global $w j$ ratios, the factors are ranked.

\section{Sources of data collection}

Data was collected from supply chain specialists having almost 10 years of practice. Supply chain experts (distribution managers, manufacturing managers, shipment officers, suppliers, retailers, and procurement administrators) from various FMCGs companies account for data collection.

The data was collected using a prescribed survey sent via email between April 12 and May 9, 2021. After analyzing the several latest studies regarding supply chain and SWARA approach, we collected the data from 18 relevant experts in the fields. While the other related studies (Singh and Modgil 2020) collected the data from just 11 relevant experts, Prajapati et al. 2019a, b collected the data from 15 relevant experts. In the study of Karuppiah et al. 2021, data of only 10 experts were used for the analysis. Gupta and Soni (2021) used the data of just 6 experts in their study. Finally, the study of Agarwal et al. 2020 used the data of just 7 experts. Thus, compared with these recent studies, we used the data of 18 experts. So, in the view of the recent research stream and according to these facts, it can be justified that data is comprehensive. Finally, for this analysis, follow the structure of (Ikram et al. 2020a, b) 18 experts from various fields, backgrounds, and geographical locations were selected. Table 2 represents the demographic profile of the professionals.

\section{Using SWARA to identify the factors and calculate the weights}

The literature review categorizes 19 critical considerations that experts have further confirmed. The current research explores a method seen in Fig. 3 for determining essential elements responsible for increasing the survival of the supply chain's sustainability and promoting the relations of buyer and supplier to face research questions.

Priorities are computed using the practices previously mentioned. On the reference chart, each professional is requested to have a weightage (Table 7 in Appendix 2). In Table 3, the measurement of geometric mean (GM) of the expert panel's preferences for the key groups is estimated. In the same way, in Table 4, the classification priorities are 
Table 2 Demographic information

\begin{tabular}{lll}
\hline Variable name & Number & Organization \\
\hline Gender & & \\
$\quad$ Female & 04 & \\
$\quad$ Male & 14 & \\
Age & & \\
$\quad 31-40$ years & 12 & \\
$\quad 41-50$ years & 06 & \\
Qualification & & \\
Bachelor & 03 & \\
Post-graduation & 15 & \\
Working experience & & \\
Less than 10 years & 0 & \\
10-12 years & 11 & \\
12-15 years & 7 & Coca-Cola \\
Expertise & & Engro Foods \\
Shipment executive & 02 & Unilever \\
Production managers & 03 & Nestle \\
Procurement (manager) & 02 & Reckitt Benckiser \\
Sales (manager) & 03 & Tobacco Company \\
Suppliers & 04 & National Foods \\
Retailor & 02 & \\
Distributors & 02 & \\
\hline
\end{tabular}

calculated. Appendix 1 shows an example of expert 1 inputs for key and decision criteria for global weight measurement (Appendix 2 Table 7, Appendix 3 Table 8). The parameters and decision criteria are arranged in Table 5 based on their relative weights Table 6 .

\section{Results and discussion}

The significance value determined using the SWARA method has been used to rate the significant features for promoting SSC viability relying on supplier-buyer associations in this evaluation. This research encourages decisionmakers, stakeholders, and firms to manage the relations of suppliers and buyers during COVID-19 to overcome supply chain issues. Table 3 shows that the COVID-19 context and the viability of the supply chain network (Crt4) are the relevant criteria for developing the supply chain's sustainability. Experts choose Crt $4>\mathrm{Crt} 5>\mathrm{Crt} 6>\mathrm{Crt} 1>\mathrm{Crt} 3>\mathrm{Crt} 2$ as the order of the parameters. Table 5 shows how their comprehensive weights estimate the various parameters for the viability of supply chain network (Crt4), which holds the

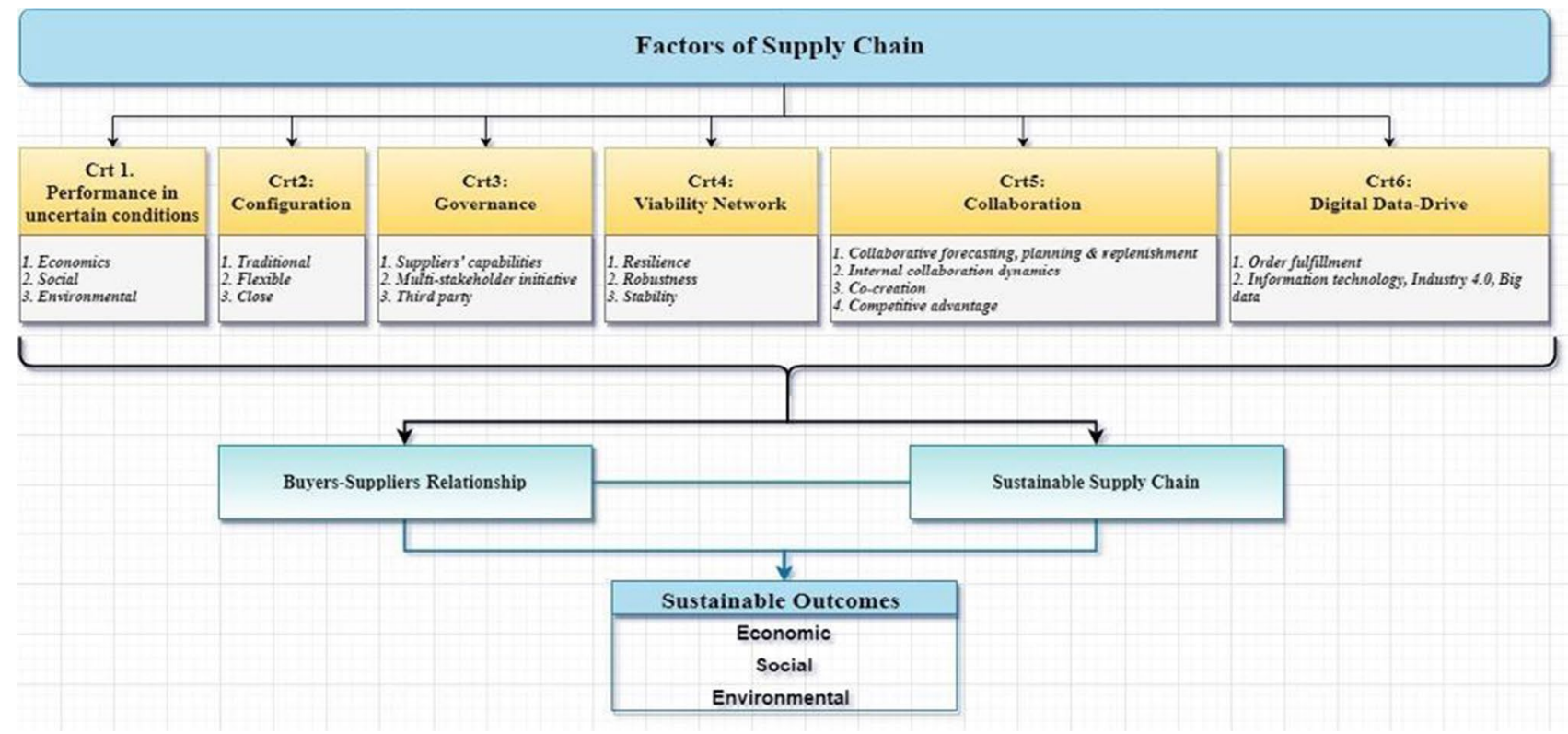

Fig. 3 Conceptual framework of sustainable supply chains in post-COVID-19

Table 3 Main criteria, estimated weightage, and rank in order

\begin{tabular}{lll}
\hline Criteria & Computed weight & Rank in order \\
\hline Crt1 - supply chain performance in uncertain conditions & 0.07992123 & 4 \\
Crt2 - configuration of supply chain (CSC) & 0.02750119 & 6 \\
Crt3 - governance of supply chain & 0.04689168 & 5 \\
Crt4 - viability of network of supply chain & 0.45465483 & 1 \\
Crt5 - collaborations of supply chain & 0.24428464 & 2 \\
Crt6 - digital data-driven SC & 0.14256124 & 3 \\
\hline
\end{tabular}


Table 4 Sub-criteria weightage

\begin{tabular}{|c|c|c|}
\hline Criteria & Sub-criteria & Weightage \\
\hline \multirow{3}{*}{$\begin{array}{l}\text { Crt1 - supply chain performance in uncer- } \\
\text { tain conditions }\end{array}$} & Crt1-1 & 0.30102 \\
\hline & Crt1-2 & 0.53621 \\
\hline & Crt1-3 & 0.16196 \\
\hline \multirow[t]{3}{*}{ Crt2 - configuration of supply chain (CSC) } & $\mathrm{Crt} 2-1$ & 0.17770 \\
\hline & Crt2-2 & 0.52359 \\
\hline & Crt2-3 & 0.29820 \\
\hline \multirow[t]{3}{*}{ Crt3-governance of supply chain } & Crt3-1 & 0.16048 \\
\hline & Crt3-2 & 0.54476 \\
\hline & Crt3-3 & 0.29429 \\
\hline \multirow[t]{3}{*}{ Crt4-viability of network of supply chain } & Crt4-1 & 0.54096 \\
\hline & Crt4-2 & 0.16372 \\
\hline & Crt4-3 & 0.29493 \\
\hline \multirow[t]{4}{*}{ Crt5 - collaborations of supply chain } & Crt5-1 & 0.49734 \\
\hline & Crt5-2 & 0.14853 \\
\hline & Crt5-3 & 0.27117 \\
\hline & Crt5-4 & 0.08240 \\
\hline \multirow[t]{2}{*}{ Crt6- digital data-driven SC } & Crt6-1 & 0.64456 \\
\hline & Crt6-2 & 0.35519 \\
\hline
\end{tabular}

maximum weight (0.4546). Beer (1981) presented the viable system model, which identifies viability as the organization's capacity to satisfy the demands of living in a dynamic atmosphere. The potential of supply chains to navigate and operate in a disruptive atmosphere by redesigning and restructuring mechanisms to develop long-term implications is considered viability. This pandemic has influenced all sectors and the market, requiring supply chain professionals to relocate to a different decision-making framework (Ivanov 2020).

Table 3 shows the weightage of the main criteria and order for the main criteria. Thus, the research illustrates during the unpredictable circumstance of COVID-19 pandemics, supply chains' instability resilience must be sustainable in surviving, stabilizing, and escaping market crashes. The efficacy of supply chains, which integrate virtual networks in dynamic structures, is frequently considered (Aubin 1991). The viability of supply chains might refer to their long-term market mobility in economies. The supply chains' sustainability in pandemics goes beyond their efficiency, earnings, or sales, and their concern for long-term viability has prompted risk management behavior (Keogh et al. 2020). Resiliency (Crt4-1), robustness (Crt4-2), and stability (Crt4-3) are the three sub-parameters of this primary criterion (Crt4). According to the findings, resiliency and stability are the two most important considerations, with global weights of (0.2459) and (0.1341), respectively. All these variables must be prioritized to improve SSC survivability. Supply chain viability (Crt4) is a complex system with structural dynamics driven by attitude, while resiliency is driven by instability. Without explicitly considering efficiency, the supreme required asset of a supply system is stability.

The supply chain must be stable to achieve resiliency (Ivanov and Dolgui 2019). COVID-19 has opened the way for supply chains to pursue new insights on resiliency and viability processes. Various behaviors are shown to transform buyer-supplier relationships to build sustainable survival. Supply chains are often reliant on the corporation

Table 5 Overall ranking of criteria and sub-criteria

\begin{tabular}{|c|c|c|c|c|c|}
\hline Criteria & Relative weight & Sub-criteria & Weightage & Global weight & Rank in order \\
\hline \multirow{3}{*}{$\begin{array}{l}\text { Crt1—supply chain performance in uncertain } \\
\text { conditions }\end{array}$} & \multirow[t]{3}{*}{0.079921} & Crt1-1 & 0.30102 & 0.0241 & 11 \\
\hline & & Crt1-2 & 0.53621 & 0.0429 & 8 \\
\hline & & Crt1-3 & 0.16196 & 0.0129 & 15 \\
\hline \multirow[t]{3}{*}{ Crt2-supply chain (CSC) } & \multirow[t]{3}{*}{0.027501} & Crt2-1 & 0.17770 & 0.0049 & 18 \\
\hline & & Crt2-2 & 0.52359 & 0.0144 & 13 \\
\hline & & Crt2-3 & 0.29820 & 0.0082 & 16 \\
\hline \multirow[t]{3}{*}{ Crt3-governance of supply chain } & \multirow[t]{3}{*}{0.046891} & Crt3-1 & 0.16048 & 0.0075 & 17 \\
\hline & & Crt3-2 & 0.54476 & 0.0255 & 10 \\
\hline & & Crt3-3 & 0.29429 & 0.0138 & 14 \\
\hline \multirow[t]{3}{*}{ Crt4-viability of network of supply chain } & \multirow[t]{3}{*}{0.45455} & Crt4-1 & 0.54096 & 0.2459 & 1 \\
\hline & & Crt4-2 & 0.16372 & 0.0744 & 5 \\
\hline & & Crt4-3 & 0.29493 & 0.1341 & 2 \\
\hline \multirow[t]{4}{*}{ Crt5-collaborations of supply chain } & \multirow[t]{4}{*}{0.24428} & Crt5-1 & 0.49734 & 0.1215 & 3 \\
\hline & & Crt5-2 & 0.14853 & 0.0363 & 9 \\
\hline & & Crt5-3 & 0.27117 & 0.0662 & 6 \\
\hline & & Crt5-4 & 0.08240 & 0.0201 & 12 \\
\hline \multirow[t]{2}{*}{ Crt6- digital data-driven SC } & \multirow[t]{2}{*}{0.14256} & Crt6-1 & 0.64456 & 0.0919 & 4 \\
\hline & & Crt6-2 & 0.35519 & 0.0506 & 7 \\
\hline
\end{tabular}


or buyer-supplier association for their survival. The collaboration of supply chain connection has the secondhighest weight (.2442) among the key parameters. The supply chain partnership works as a method for reducing the impact of the bullwhip effect. As a result, the supply chain must create an inclusive and vigorous configuration to meet consumer demands, assisted by cooperation among supply chain members. The critical criterion of collaboration of supply chain (Crt5) is divided into four sub-categories: collaborative strategy, replenishment and forecasting (Crt5-1), interior coordination (Crt5-2), supply chain co-creation (Crt5-3), and competitive edge (Crt5-4).

The sub-criteria are the measurement items for the main criteria. Each main criteria has three to four sub-criteria. However, experts are requested to choose and gave weightage according to their priorities. The main criteria and sub-criteria support each other in calculating weightage that will be the base of ranking. Based on the estimated scale, one would be able to choose the criteria for decision. So, the main criteria, sub-criteria, and weightage are mentioned in Table 4.

Table 5 shows that forecasting, preparation, and replenishment in collaboration (Crt5-1) and supply chain co-creation (Crt5-3) having a loading of (0.1216) and (0.0663), accordingly, which demonstrate that all these considerations are essential in managing the relationship of buyer and supplier and optimizing SSCs stability. FPRC (forecasting, preparation, and replenishment in collaboration) (Crt5-1) is a market operation that brings together the intelligence of many supply chains to practice forecasting and planning to improve demand insight and performance (Ni and Sun 2018). Basic demand and supply are beyond the bounds of what supply chains are built for, so FPRC can rely on estimating or evaluating demand. The supply chains should start a unique market forecast that assures projection accuracy and adequate supply for the basics that are in high demand. As the COVID-19 spreads to new places, the global and local supply chains must implement mitigation and alternative plans. The companies see sustainability as a competitive opportunity for associating with suppliers (Singhry and Rahman 2019). Supply chain co-creation in supply chains aims to enhance the process and product while making improvements. Data-driven supply chains are meeting consumer needs by delivering essentials goods to shops at their doorsteps. Supply chains adopt just-in-time and order fulfillment distribution solutions for quarantine, limited-time retail operations, stayat-home orders, and self-isolation. Supply chains are now reducing the number of goods they provide to concentrate on completing orders on schedule and in a clean and sanitary manner. Many companies have implemented sameday or next-day service delivery, with extra employees and tie-ups temporary have also been planned.
Consumers have enhanced their consumption of health and wellbeing items, products required for virus protection, and protection steps such as masks and gloves due to the terrifying situation around the world. Resource management at the local level must be considered to avoid stock-out conditions and control order fulfillment to balance supply and demand. One of the most important things for businesses to work during a pandemic is their societal success under instability. The coronavirus has introduced a modern work philosophy focused on achieving organizational productivity by flexible working hours and remote work worldwide. This may be a chance for business operations like eBay, Google, Amazon, and others to contribute to the economy by promoting platforms for job creation and upholding their corporate duty to ensure the welfare of their workers.

\section{Conclusion and implications}

This research investigates the substantial aspects for attracting the survival of SSC and maintaining the relations of buyer and supplier. There is no single aspect on which the supply chains can depend exclusively on this pandemic. Still, the current focus on market delivery resiliency, datadriven market delivery, stability, order fulfillment strategies, and supplier cooperation could be fruitful. Consumers increasingly adopt contactless or online order solutions due to fear of transmission in public spaces and social distancing, providing the basis for supply chains sustainability to develop in the post-COVID-19 era. This study looks at the prospects for supply chains, the human-machine ratio, and the use of hybrid models and operational processes. This research helps create collaborative, integrated, and supply chain sustainability during and post-COVID-19 scenarios, and companies that neglect excellent customer support' having the risk of losing business and ultimately extinction.

Pandemics seem to be the most critical attribute of market instability. COVID-19 has incorporated a lift-it-up of insubstantiality, but effective means of maintaining supply chains could have changed forever. To enhance long-term economic and social benefits, supply chains must update their strategic direction to respond to technology changes, social environment, and transform their business structures, including various networks. The main drivers for FMCGs businesses to succeed and thrive in pre-and post-COVID-19 circumstances are viability, resiliency, order fulfillment/justin-time, stability, data analytics, teamwork, convergence, demand forecasting, and real-time intelligence. Practical, durable supply chains engage distributors and other stakeholders in an inclusive and accountable mechanism that promotes the long-term progress of FMCGs. For FMCGs organization's success, resilient supply chains must be designed across proper demand scheduling, monitoring, distribution 
network, supplier meetings, supplier cooperation, and predicting the impact of economic and social conditions. Since coronavirus has a long-term effect on supply chains, it's essential to know several shipping methods. The integration of a shipping distribution approach would reduce costs and prioritize a safe inventory stock supply strategy, which will help FMCGs supply chains survive.

There are some limitations of this research. First, an SSC that is evaluated could be biased due to a panel of experts. To ensure that the findings are robust, a responsive analysis may be used. Additionally, empirical experiments may be used to validate the research. Furthermore, customers were excluded from the expert groups selected for data collection for this study; thus, it would be appropriate to collect data and get consumer details from retailers who acquired goods during and after the COVID-19 pandemic. So, it may increase the expert group's integrity and support the results of this analysis.

\section{Managerial/ Practical implication}

This research assists in determining the most major elements of management. The findings also help to identify the key factors that firms might use to improve supply chain resilience and robustness by assessing the combinations of SSCs. Sustainability is one of the essential characteristics, not only in terms of economic considerations but also in terms of all other factors. Supply chain, risk management, supplier evaluation, strategy implementation, and so on are only a few of the key elements to consider when deciding. Two aspects of the research seem to be used to examine variables that affect SSCs and buyer-supplier connections. First, this study aims to look at the social, economic, and environmental impacts on enterprises to improve the long-term efficacy of SSCs. Since COVID-19 has long-term consequences on global economies, the study indicates that supply chains must become sustainable to survive and succeed in the long run. The factors determined in this study can be used in future projects as well as for organizational decision-making. In this study, the framework incorporating SWARA will assist decision-makers in understanding the several bottlenecks that arise when moving toward sustainability and making strong relationships with buyers. It is critical to be aware of different elements beneficial to a long-term supply chain in the post-COVID-19 scenario. With the help of a particular solution, this research helps decision-makers successfully minimize hurdles and prepare to implement powerful, strong connections, and dynamic supply chain sustainability.

Supply chains in the FMCGs industry must adapt to new socio-economic needs to succeed and thrive in the long run. The social responsibilities are also exhausting FMCGs managers to improve their supply chains with several problems, such as labor shortages, uncertain competitive pressures, extended working hours for employees, maintaining social distancing across massive crowds, treating visitors' arriving without masks, and gloves. If some of these issues are not overcome, it will almost certainly result in business failure shortly. As a result, viable supply chains can cope with such instabilities before and after COVID-19. Supply chains in the FMCGs industry must control demand and inventory in the short and long term using advanced technologies such as big data analytics to manage orders based on real-time data and the Internet of Things (Raut et al. 2019) to mitigate manufacturing losses, plant shutdowns, and economic downturn. These strategies contribute not only to improving operating efficiency in the short term but also in strengthening their supply chains in the long term to cope with the post-COVID-19 condition. The global atmosphere requires customers to remain at home, retain social distance, and maintain hygiene, resulting in an immediate increase in handling supply chains to meet the demand for necessities. Such as sanitary wipes, gloves, soaps, masks, disinfect devices, immune-boosting drugs, and other products, in-store sales should be maintained where online distribution is not meeting demand.

Furthermore, it is not possible to incorporate all factors into solutions that assist decision-makers in focusing on solutions that give the best results. This factor increases the likelihood of effective relationships and sustainability. In this critical situation, a supply chain that focuses on cooperation with suppliers, resiliency, robustness, and innovative data analytics for value addition is more efficient. To succeed and thrive in a postpandemic situation, FMCGs businesses must find their way to the digital transformation of supply chain practices.

Second, the SWARA framework may provide significant legislation to decision-makers and specialists to build up their short- and long-term activities to create an SSC. SSCs must adjust strategies accordingly as the social climate and environmental circumstances change in most countries, such as Pakistan and India, where the living process is constrained. As the pandemic spreads worldwide, the transformation of a new supply chain environment for online shopping, click and collect, contactless distribution services, and increased product segment intake. As a result, order fulfillment at the customer's doorstep is becoming more attractive to shoppers who want to avoid crowds, long lines, and security concerns. "Resiliency, robustness, and new data analytics for value addition" are at the top of the priority list of solutions. As a result, industries should insist on these characteristics to increase their supply chain's performance and long-term viability. Supply chains of FMCGs businesses should concentrate on resiliency and viability in a "modern standard" situation, transitioning into a digital industry to provide social and economic benefits to society and turning into a network platform for positive impact on society. The COVID-19 catalyzes the creation of resilient, secure supply chains that can respond to any crisis. The study offers FMCGs insights into developing new strategies based on 
changing consumer trends and personality traits that would be successful in post-COVID-19 scenarios, including evolving consumer interest in social media platforms, inventory management, regular sanitization, and social media distancing, and employee knowledge of sanitation and social safety precautions. To cope with these problems, businesses spread workforce awareness activities on health and sanitation through many networking channels. The supply chain's approach to teamwork, resilience, order fulfillment, and data mining to survive in COVID-19 pandemics is critical Tables 7 and 8.

\section{Appendix 1}

Table 6 Main criteria and sub-criteria

\begin{tabular}{|c|c|c|c|c|c|c|c|c|c|c|c|c|c|}
\hline $\begin{array}{l}\text { Main } \\
\text { criteria }\end{array}$ & $\begin{array}{l}\text { Relative } \\
\text { signifi- } \\
\text { cance }\end{array}$ & $\begin{array}{l}\text { Sub- } \\
\text { criteria } \\
\text { Crt1 }\end{array}$ & $\begin{array}{l}\text { Relative } \\
\text { signifi- } \\
\text { cance }\end{array}$ & $\begin{array}{l}\text { Sub- } \\
\text { criteria } \\
\text { Crt2 }\end{array}$ & $\begin{array}{l}\text { Relative } \\
\text { signifi- } \\
\text { cance }\end{array}$ & $\begin{array}{l}\text { Sub- } \\
\text { criteria } \\
\text { Crt3 }\end{array}$ & $\begin{array}{l}\text { Relative } \\
\text { signifi- } \\
\text { cance }\end{array}$ & $\begin{array}{l}\text { Sub- } \\
\text { criteria } \\
\text { Crt4 }\end{array}$ & $\begin{array}{l}\text { Relative } \\
\text { signifi- } \\
\text { cance }\end{array}$ & $\begin{array}{l}\text { Sub- } \\
\text { criteria } \\
\text { Crt5 }\end{array}$ & $\begin{array}{l}\text { Relative } \\
\text { signifi- } \\
\text { cance }\end{array}$ & $\begin{array}{l}\text { Sub- } \\
\text { criteria } \\
\text { Crt6 }\end{array}$ & $\begin{array}{l}\text { Relative } \\
\text { significance }\end{array}$ \\
\hline Crt1 & & Crt1-01 & & Crt2-01 & & Crt3-01 & & Crt4-01 & & Crt5-01 & & Crt6-01 & \\
\hline Crt2 & & Crt1-02 & & Crt2-02 & & Crt3-02 & & Crt4-02 & & Crt5-02 & & Crt6-02 & \\
\hline Crt3 & & Crt1-03 & & Crt2-03 & & Crt3-03 & & Crt4-03 & & Crt5-03 & & & \\
\hline Crt4 & & & & & & & & & & $5-04$ & & & \\
\hline \multicolumn{14}{|l|}{ Crt5 } \\
\hline Crt6 & & & & & & & & & & & & & \\
\hline
\end{tabular}

\section{Appendix 2}

Table 7 Stepwise average ratio analysis of expert 1, calculation of data

\begin{tabular}{lllll}
\hline Central criteria & $s j$ & $k j$ & $q j$ & wj \\
\hline Crt4 & .00 & 1.00 & 1.0000 & .46444 \\
Crt5 & .91 & 1.91 & .52633 & .24444 \\
Crt6 & .81 & 1.81 & .29238 & .13578 \\
Crt1 & .81 & 1.81 & .16245 & .07545 \\
Crt3 & .51 & 1.51 & .10828 & .05028 \\
Crt2 & .71 & 1.71 & .06371 & .02959 \\
\hline
\end{tabular}




\section{Appendix 3}

Table 8 Calculation sub-criteria by stepwise average ratio analysis, data of expert 1

\begin{tabular}{lllll}
\hline Sub-criteria & $\mathrm{sj}$ & $k j$ & $q j$ & $w j$ \\
\hline Crt1-01 & .00 & 1.00 & 1.0000 & .56094 \\
Crt1-02 & .96 & 1.96 & .5128 & .28767 \\
Crt1-03 & .92 & 1.92 & .2698 & .15141 \\
Crt2-01 & .00 & 1.00 & 1.0000 & .51128 \\
Crt2-02 & .72 & 1.72 & .5883 & .30076 \\
Crt2-03 & .61 & 1.61 & .3677 & .18797 \\
Crt3-01 & .00 & 1.00 & 1.0000 & .54984 \\
Crt3-02 & .92 & 1.92 & .5264 & .28939 \\
Crt3-03 & .81 & 1.81 & .2924 & .16078 \\
Crt4-01 & .00 & 1.00 & 1.0000 & .54322 \\
Crt4-02 & .87 & 1.87 & .5406 & .29364 \\
Crt4-03 & .82 & 1.82 & .3004 & .16314 \\
Crt5-01 & .00 & 1.00 & 1.0000 & .51743 \\
Crt5-02 & .96 & 1.96 & .5120 & .26535 \\
Crt5-03 & .91 & 1.91 & .2698 & .13966 \\
Crt5-04 & .81 & 1.81 & .1498 & .07757 \\
Crt6-01 & .00 & 1.00 & 1.0000 & .66104 \\
Crt6-02 & .96 & 1.96 & .5129 & .33899 \\
\hline
\end{tabular}

Author contributions Conceptualization: K.H.; formal statistical analysis: K.H.; Data collection: K.H and M.A.K.; Investigation: K.H; methodology: K.H and M.A.K.; supervision: Z.JJ. and S.A.; writing final draft: K.H.; review and editing: K.H., Z.JJ., and S.A.

Funding The study is supported by the National Natural Science Foundation of China; Grant no. (71502073).

Data Availability: The datasets/materials used and analyzed for the present manuscript are available from the corresponding author on reasonable request.

\section{Declarations}

Conflict of interest The authors declare no competing interests.

Consent to participate I am free to contact any research people to seek further clarification and information.

\section{References}

Agrawal S, Singh P, Mazumdar M (2021) Innovation, firm size and ownership: a study of firm transition in India. Int J Global Business Competitiveness 16:15-27. https://doi.org/10.1007/s42943-021-00022-y

Agarwal S, Kant R, Shankar R (2020) Evaluating solutions to overcome humanitarian supply chain management barriers: a hybrid fuzzy SWARA - Fuzzy WASPAS approach. Int J Disaster Risk Reduct 51(August 2019):101838. https://doi.org/10.1016/j.jjdrr.2020.101838

Albors-Garrigos J (2020) barriers and enablers for innovation in the retail sector: co-innovating with the customer. A case study in grocery retailing. J Retailing Consumer Services 55:102077

Alghababsheh M, Gallear D (2020) Socially Sustainable supply chain management and suppliers' social performance: the role of social capital. J Business Ethics 163:125-150. https://doi.org/10.1007/ s10551-018-3993-0

Araz OM, Choi TM, Olson DL, Salman FS (2020) Role of analytics for operational risk management in the era of big data. Decision. https://doi.org/10.1111/deci.12451

Ashby A, Leat M, Hudson-Smith M (2012) Making connections: a review of supply chain management and sustainability literature. Supply Chain Manag: Int J 17(5):497-516

Aßländer MS, Roloff J, Nayır DZ (2016) Suppliers as stewards? managing social standards in first- and second-tier suppliers. J Business Ethics 139(4):661-683

Aubin JP (1991) Viability Theory. Birkhäuser, Boston

Badraoui I, Van der Vorst JG, Boulaksil Y (2020) Horizontal logistics collaboration: an exploratory study in Morocco's agri-food supply chains. Int J Logistics Res Appl 23(1):85-102

Barbosa-Póvoa AP, da Silva C, Carvalho A (2018) Opportunities and challenges in sustainable supply chain: an operations research perspective. Eur J Operational Res 268(2):399-431. https://doi. org/10.1016/J.EJOR.2017.10.036

Barrow CJ (2018) Sustainable development. Int Encyclopedia Anthropol. https://doi.org/10.1002/9781118924396.wbiea1463

Beer S (1981) Brain of the Firm, 2nd edn. Chichester, John Wiley \& Sons

Beske P, Seuring S (2014) Putting sustainability into supply chain management. Supply Chain Manag 19(3):322-331. https://doi.org/10. 1108/SCM-12-2013-0432

Blackhurst J, Dunn KS, Craighead CW (2011) An empirically derived framework of global supply resiliency. J Business Logistics 32(4):374-391

Blome C, Paulraj A, Schuetz K (2014) Supply chain collaboration and sustainability: a prodfileviation analysis. Int J Operations Product Manag 34(5):639-663

Bodi-Schubert A (2014) The conceptual model of success in buyersupplier relationship. IMP J 8(1):31-43

Brandenburg M, Govindan K, Sarkis J, Seuring S (2014) Quantitative models for sustainable supply chain management: developments and directions. Eur J Operational Res 233(2):299-312. https:// doi.org/10.1016/J.EJOR.2013.09.032

Brandenburg M, Gruchmann T, Oelze N (2019) Sustainable supply chain management - a conceptual framework and future research perspectives. Sustainability 11(24):7239. https://doi.org/10.3390/ su11247239 
Busse C (2016) Doing well by doing good? The self-interest of buying firms and sustainable supply chain management. J Supply Chain Manag 52(2):28-47

Carbone V, Moatti V, Vinzi VE (2012) Mapping corporate responsibility and sustainable supply chains: an exploratory perspective. Business Strategy Environ 21(7):475-494

Carter CR, Easton PL (2011) Sustainable supply chain management: evolution and future directions. Int J Phys Distrib Logistics Manag 41(1):46-62. https://doi.org/10.1108/09600031111101420

Carvalho H, Cruz-Machado V, Tavares JG (2012) A mapping framework for assessing supply chain resilience. Int J Logistics Syst Manag 12(3):354-373

Chakraborty K, Mondal S, Mukherjee K (2018) Developing a causal model to evaluate the critical issues in reverse supply chain implementation. Benchmarking: Int J 25(7):1992-2017

Chapman P, Christopher M, Jüttner U, Peck H, Wilding R (2002) Identifying and managing supply chain vulnerability. Logistics Transport Focus 4(4):59-64

Chen L, Zhao X, Tang O, Price L, Zhang S, Zhu W (2017) Supply chain collaboration for sustainability: a literature review and future research agenda. Int J Product Econ 194:73-87

Chi M, Huang R, George JF (2020) Collaboration in demand-driven supply chain: based on a perspective of governance and IT-business strategic alignment. Int J Inform Manag 52:102062

Choi TM, Guo S (2020) Is a l'Furneech'a good lunch? The performance of zero wholesale price-based supply-chain contracts. Eur J Operational Res 285(1):237-246

Cohen MJ (2020) Does the COVID-19 outbreak mark the onset of a sustainable consumption transition? Sustainability: Science. Pract Policy 16(1):1-3. https://doi.org/10.1080/15487733.2020. 1740472

Dania WAP, Xing K, Amer Y (2019) An integrated collaboration framework for sustainable sugar supply chains. Int J Supply Chain Manag 8(3):706-717

Demirel G, MacCarthy BL, Ritterskamp D, Champneys AR, Gross $\mathrm{T}$ (2019) Identifying dynamical instabilities in supply networks using generalized modeling. J Operations Manag 65(2):136-159

Dolgui A, Ivanov D, Rozhkov M (2020) Does the ripple effect influence the bullwhip Effect? An integrated analysis of structural and operational dynamics in the supply chain. Int J Product Res 58(5):1285-1301

Dubey R, Gunasekaran A, Papadopoulos T, Childe SJ, Shibin KT, Wamba SF (2017) Sustainable supply chain management: framework and further research directions. J Cleaner Prod 142:1119-1130

Dun \& Bradstreet. 2020. Accessed March 10, 2020. https://foreignpol icy.com/2020/03/04/blindsided-on-the-supply-side/.

Eggers JE, Hofman E, Schiele H, Holschbach E (2017) Identifying the 'right' supplier for module developments - a cross-industrial case analysis. Int J Innov Manag 21(3): 1750026

Feizabadi J, Gligor D, Alibakhshi Motlagh S (2019) The tripleas supply chain competitive advantage. Benchmarking: Int J 26(7):2286-2317

Fortune (2020) Accessed March 10, 2020. https://fortune.com/2020/ 02/21/fortune-1000-coronavirus-china-supply- chain-impact/.

Gandhi S, Mangla SK, Kumar P, Kumar D (2016) A combined approach using AHP and DEMATEL for evaluating success factors in implementation of green supply chain management in Indian manufacturing industries. Int J Logistics Res Appl 19(6):537-561

Gereffi G, Lee J (2016) Economic and social upgrading in global value chains and industrial clusters: why governance matters. J Business Ethics 133(1):25-38

Guan Z, Zhang X, Zhou M, Dan Y (2020) Demand information sharing in competing supply chains with manufacturer-provided service. Int J Product Econ 220:107450
Gupta N, Soni G (2021) A decision -making framework for sustainable supply chain finance in post -COVID era. Int J Global Business Competitiveness, (0123456789. https://doi.org/10.1007/ s42943-021-00028-6

Handfield RB, Graham G, Burns L (2020) Corona virus, tariffs, trade wars and supply chain evolutionary design, Int J Oper Product Manag

Harms D, Hansen EG, Schaltegger S (2013) Strategies in sustainable supply chain management: an empirical investigation of large German companies. Corporate Social Responsibil Environ Manag 20(4):205-218

Hayat K, Jianjun Z, Zameer H, Iqbal S (2020) Understanding the influence of corporate social responsibility practices on impulse buying. Corporate Social Responsibil Environ Manag 27(3): 1454-1464

Hoang L, Blank G, Quan-Haase A (2020) The winners and the losers of the platform economy: who participates? Inform Commun Soc 23(5):681-700. https://doi.org/10.1080/1369118X.2020.1720771

Hofmann E, Rutschmann E (2018) Big data analytics and demand forecasting in supply chains: a conceptual analysis. Int J Logistics Manag 29(2):739-766

Holgado de Frutos E, Trapero JR, Ramos F (2020) A literature review on operational decisions applied to collaborative supply chains. PloS one 15(3):e0230152

Hollmann RL, Scavarda LF, Thomé AMT (2015) Collaborative planning, forecasting and replenishment: a literature review. Int J Product Performance Manag 64(7):971-993

Holmstr€om, J. and Gutowski, T. (2017) Additive manufacturing in operations and supply chain management: no sustainability benefit or virtuous knock-on opportunities? J Industrial Ecol 21(S1):S21-S24

Hosseini S, Ivanov D, Dolgui A (2019) Review of quantitative methods for supply chain resilience analysis. Transport Res Part E: Logistics Transport Rev 125:285-307

Hughes DE, Richards KA, Calantone R, Baldus B, Spreng RA (2019) Driving in-role and extra-role brand performance among retail frontline salespeople: antecedents and the moderating role of customer orientation. J Retailing 95(2):130-143

Iftikhar R, Khan MS (2020) Social media big data analytics for demand forecasting: development and case implementation of an innovative framework. J Global Inform Manag 28(1):103-120

Ikram M, Mahmoudi A, Shah SZA, Mohsin M (2019) Forecasting number of ISO 14001 certifications of selected countries: application of even GM $(1,1)$, DGM, and NDGM models. Environ Sci Pollut Res, (Iea 2015). https://doi.org/10.1007/ s11356-019-04534-2

Ikram M, Zhang Q, Sroufe R, Ferasso M (2020a) The social dimensions of corporate sustainability: an integrative framework including COVID-19 insights. Sustainability (Switzerland) 12(20):1-29. https://doi.org/10.3390/su12208747

Ikram M, Zhang Q, Sroufe R, Shah SZA (2020b) Towards a sustainable environment: the nexus between ISO 14001, renewable energy consumption, access to electricity, agriculture and $\mathrm{CO}_{2}$ emissions in SAARC countries. Sustainable Product Consumpt 22:218-230. https://doi.org/10.1016/j.spc.2020.03.011

Ikram M, Zhang Q, Sroufe R, Ferraso M (2021) Contribution of Certification bodies and sustainability standards to sustainable development goals: an integrated grey systems approach. Sustainable Production and Consumption

Prajapati H, Kant R, Shankar R (2019a) Prioritizing the solutions of reverse logistics implementation to mitigate its barriers: a hybrid modified SWARA and WASPAS approach. J Cleaner Product 240:118219. https://doi.org/10.1016/j.jclepro.2019.118219

Ishfaq R, Bajwa N (2019) Profitability of online order fulfillment in multi-channel retailing. Eur J Operational Res 272(3):1028-1040 
Ishfaq R, Raja U (2018) Evaluation of order fulfillment options in retail supply chains. Decision Sci 49(3):487-521

Ivanov D (2020) Predicting the impacts of epidemic outbreaks on global supply chains: a simulation-based analysis on the coronavirus outbreak (COVID-19/SARS-CoV-2) case. Transport Res Part E: Logistics Transport Rev 136:101922

Ivanov D, Dolgui A (2019) Low-certainty-need (LCN) supply chains: a new perspective in managing disruption risks and resilience. Int J Product Res 57(15-16):5119-5136. https://doi.org/10.1080/ 00207543.2018 .1521025

Ivanov D, Dolgui A (2020) Viability of intertwined supply networks: extending the supply chain resilience angles towards survivability. A position paper motivated by COVID-19 outbreak. Int J Product Res 58(10):2904-2915. https://doi.org/10.1080/00207 543.2020.1750727

Ivanov D, Sethi S, Dolgui A, Sokolov B (2018) A survey on control theory applications to operational systems, supply chain management, and industry 4.0. Annual Rev Control 46:134-147

Ivanov D, Sokolov B, Kaeschel J (2010) A multi-structural framework for adaptive supply chain planning and operations control with structure dynamics considerations. Eur J Operational Res 200(2):409-420

Karabasevic D, Stanujkic D, Urosevic S, Maksimovic M (2015) Selection of candidates in the mining industry based on the application of the SWARA and the MULTIMOORA methods. Acta Montan Slovaca 20(2):116-124

Karuppiah K, Sankaranarayanan B, Ali SM, Paul SK (2021) Key challenges to sustainable humanitarian supply chains: lessons from the covid-19 pandemic. Sustainability (Switzerland) 13(11):120. https://doi.org/10.3390/su13115850

Keogh JG, Rejeb A, Khan N, Dean K, Hand KJ (2020) nDd aFtoaod supply chain: blockchain and GS1 standards in the food chain: a review of the possibilities and challenges. Building Future Food Safety Technol 145:145-178. https://doi.org/10.1016/B978-012-818956-6.000075

Klewitz J, Hansen EG (2014) Sustainability-oriented innovation of SMEs: a systematic review. J Cleaner Product 65(57):75. https:// doi.org/10.1016/j.jclepro.2013.07.017

Konstantaras I, Skouri K, Lagodimos AG (2019) EOQ with independent endogenous supply disruptions. Omega 83:96-106. https:// doi.org/10.1016/j.omega.2018.02.006

KPMG (2020) COVID-19 surveillance challenges. Accessed May 9, 2020. https://home.kpmg/xx/en/blogs/home/ posts/2020/04/ surveillance-challenges-under-covid-19.html

Kudla NL, Klaas-Wissing T (2012) Sustainability in shipper-logistics service provider relationships: a tentative taxonomy based on agency theory and stimulus-response analysis. J Purchasing Supply Manag 18(4):218-231

Kumar D (2019) Buyer-supplier relationship selection for a sustainable supply chain: a case of the Indian automobile industry. Int J Analytic Hierarchy Process 11(2):215-227

Kumar D, Rahman Z (2016) Buyer supplier relationship and supply chain sustainability: empirical study of Indian automobile industry. J Cleaner Product 131:836-848

Leszczynska A (2018) Sustainable supply chain capabilities - factors stimulating the processes and organizational performance. Int J Sustain Econ 10(3):263-282

Li B, Jiang Y (2019) Impacts of returns policy under supplier encroachment with risk-averse retailer. J Retailing Consumer Services 47:104-115

Li Y, Zobel CW (2020) Exploring supply chain network resilience in the presence of the ripple effect. Int J Product Econ 228:107693. https://doi.org/10.1016/j.ijpe.2020.107693

Linton T, Vakil B (2020) Coronavirus is proving we need more resilient supply chains. Harward Business Review, March 5. Accessed March 10, 2020
Lintukangas K, Hallikas J, Kähkönen AK (2015) The role of green supply management in the development of sustainable supply chain. Corporate Social Responsibil Environ Manag 22(6):321-333

Liu CL, Lee MY (2018) Integration, supply chain resilience, and service performance in third-party logistics providers. Int J Logistics Manag 29(1):5-21

Madsen SM, Petermans A (2020) Exploring the system of digitized retail design-flattening the ontology. J Retailing Consumer Services 54:102053

Marques L (2019) Sustainable supply network management: a systematic literature review from a knowledge perspective. Int J Product Performance Manag 68(6):1164-1190

McKinsey (2020) McKinsey. Accessed May 9, 2020. COVID-19: implications for business. https://www. mckinsey.com/ business-functions/risk/our-insights/ covid-19-implications-for-business

Mehranfar N, Hajiaghaei-Keshteli M, Fathollahi-Fard AM (2019) A novel hybrid whale optimization algorithm to solve a production distribution network problem considering carbon emissions. Int J Eng 32:1781-1789. https://doi.org/10.5829/ije.2019.32.12c.11

Merminod N, Paché G (2011) Supply management and corporate social responsibility: the challenge of global chain traceability. J Chain Network Sci 11(3):213-222

Nakano M, Matsuyama K (2020) Internal supply chain structure design: a multiple case study of japanese manufacturers. Int $\mathbf{J}$ Logistics Res Appl 1-23. https://doi.org/10.1080/13675567. 2020.1726305.

Nandi S, Sarkis J, Hervani AA, Helms MM (2021) Redesigning Supply Chains using Blockchain-Enabled Circular Economy and COVID-19 Experiences. Sustain Prod Consum 27:10-22. https:// doi.org/10.1016/J.SPC.2020.10.019

Nazam M, Hashim M, Randhawa MA, Maqbool A (2020) Modeling the barriers of sustainable supply chain practices: a Pakistani perspective. Advances Intell Syst Comput 1002(2):348-364

Negri M, Cagno E, Colicchia C, Sarkis J (2021) Integrating sustainability and resilience in the supply chain: a systematic literature review and a research agenda. Business Strat Environ, (February), 1-29. https://doi.org/10.1002/bse.2776

Nezhadroshan AM, Fathollahi-Fard AM, Hajiaghaei-Keshteli M (2020) A scenario-based possibilistic-stochastic programming approach to address resilient humanitarian logistics considering travel time and resilience levels of facilities. Int J Syst Sci: Operations Logistics. https://doi.org/10.1080/23302674.2020.1769766

Ni W, Sun H (2018) A contingent perspective on the synergistic effect of governance mechanisms on sustainable supply chain. Supply Chain Manag: Int J 23(3):153-170

Pakdeechoho N, Sukhotu V (2018) Sustainable supply chain collaboration: incentives in emerging economies. J Manufact Technol Manag 29(2):273-294

Panahifar F, Shokouhyar S (2019) An interpretive structural modelling of enablers for collaborative planning, forecasting and replenishment implementation in high-tech industries. Int J Inform Decision Sci 11(1):55-72

Pankowska M (2019) Information technology outsourcing chain: literature review and implications for development of distributed coordination. Sustainability 11(5):1460

Patel AB, Desai TN (2019) A systematic review and meta-analysis of recent developments in sustainable supply chain management. Int J Logistics Res Appl 22(4):349-370

Paul SK, Sarker R, Essam D (2018) A reactive mitigation approach for managing supply disruption in a three-tier supply chain. J Intell Manuf 29(7):1581-1597. https://doi.org/10.1007/ s10845-016-1200-7

Pavlov A, Ivanov D, Pavlov D, Slinko A (2019) Optimization of network redundancy and contingency planning in sustainable and resilient supply chain resource management under conditions of 
structural dynamics. Annals Operations Res:1-30. https://doi. org/10.1007/s10479-019-03182-6

Peck H (2005) Drivers of supply chain vulnerability: an integrated framework. Int J Phys Distrib Logistics Manag 35(4):210-232

Pettit TJ, Croxton KL, Fiksel J (2019) The evolution of resilience in supply chain management: a retrospective on ensuring supply chain resilience. J Business Logistics 40(1):56-65

Prajapati H, Kant R, Shankar R (2019b) Prioritizing the solutions of reverse logistics implementation to mitigate its barriers: a hybrid modified SWARA and WASPAS approach. J Cleaner Product 240:118219

Prince M, Kwak L, Priporas CV (2019) The diogenes effect in retail buyer information processing. J Retailing Consumer Services 49:164-172

RAI (2020) Retailer Association of India. Accessed May 13, 2020 rai. net.in: http://www.businessworld.in/article/RAI-Survey-Resul ts-Impact-of-Covid-19-on-Indian Retailers/07-04-2020-188501/.

Rajeev A, Pati RK, Padhi SS, Govindan K (2017) Evolution of sustainability in supply chain management: a literature review. J Cleaner Product 162:299-314. https://doi.org/10.1016/J.JCLEP RO.2017.05.026

Ralston P, Blackhurst J (2020) Industry 4.0 and resilience in the supply chain: a driver of capability enhancement or capability loss? Int J Product Res 58:1-14. https://doi.org/10.1080/00207543.2020. 1736724

Rao S, Griaffinsd SE, Goldsby TJ (2011) Failure to deliver? Linking online order fulfillment glitches with future purchase behavior. J Operations Manag 29(7-8):692-703

Raut RD, Mangla SK, Narwane VS, Gardas BB, Priyadarshinee P, Narkhede BE (2019) Linking big data analytics and operational sustainability practices for sustainable business management. J Cleaner Product 224:10-24

Reinecke J, Manning S, Von Hagen O (2012) The emergence of a standards market: multiplicity of sustainability standards in the global coffee industry. Organization Studies 33(5-6):791-814

Reuter C, Foerstl KAI, Hartmann EVI, Blome C (2010) Sustainable global supplier management: the role of dynamic capabilities in achieving competitive advantage. J Supply Chain Manag 46(2):45-63

Roy A, Sana SS, Chaudhuri K (2018) Optimal pricing of competing retailers under uncertain demand-a two layer supply chain model. Annals Operations Res 260(1-2):481-500

Roy V, Silvestre BS, Singh S (2020) Reactive and proactive pathways to sustainable apparel supply chains: manufacturer's perspective on stakeholder salience and organizational learning toward responsible management. Int J Product Econ 227:107672. https:// doi.org/10.1016/J.IJPE.2020.107672

Sarkis J, Cohen MJ, Dewick P, Schröder P (2020) A brave new world: lessons from the COVID-19 pandemic for transitioning to sustainable supply and production. Resources, Conserv Recycling 159:104894

Sauer PC, Seuring S (2017) Sustainable supply chain management for minerals. J Cleaner Product 151:235-249

Scharmer O (2020) Eight emerging lessons: from coronavirus to climate action, The Medium, available at: lessons-fromcoronavirus- to-climate-action-683c39c10e8b

Schoenmaker D (2019) A framework for sustainable finance. https:// doi.org/10.2139/ssrn.3125351

Scholten K, Sharkey Scott P, Fynes B (2019) Building routines for non-routine events: supply chain resilience learning mechanisms and their antecedents. Supply Chain Manag: Int J 24(3):430-442

Seuring S (2013) A review of modeling approaches for sustainable supply chain management. Decision Support Syst 54(4):1513-1520. https://doi.org/10.1016/j.dss.2012.05.053
Seuring S, Müller M (2008) From a literature review to a conceptual framework for sustainable supply chain management. J Cleaner Product 16(15):1699-1710. https://doi.org/10.1016/j.jclepro. 2008.04.020

Simchi-Levi D, Wang H, Wei Y (2018) Increasing supply chain robustness through process flexibility and inventory. Product Operations Manag 27(8):1476-1491

Singh RK, Modgil S (2020) Supplier selection using SWARA and WASPAS - a case study of Indian cement industry. Measuring Business Excell 24(2):243-265. https://doi.org/10.1108/ MBE-07-2018-0041

Singhry HB, Rahman AA (2019) Enhancing supply chain performance through collaborative planning, forecasting, and replenishment. Business Process Manag J 25(4):625-646

Svensson G (2004) Vulnerability in business relationship: the gap between dependance and trust. J Business Industrial Market 19(7):469-483

Tachizawa EM, Wong CY (2014) Towards a theory of multi-tier sustainable supply chains: a systematic literature review. Supply Chain Manag: An Int J 19(5/6):643-663

Thakur V, Mangla SK (2019) Change management for sustainability: evaluating the role of human, operational and technological factors in leading indian firms in home appliances sector. J Cleaner Product 213:847-862

Thiagarajan K (2021) Why is India having a covid-19 surge? BMJ (Clin Res Ed.) 373:n1124. https://doi.org/10.1136/bmj.n1124

Tidy M, Wang X, Hall M (2016) The role of supplier relationship management in reducing greenhouse gas emissions from food supply chains: supplier engagement in the U.K. Supermarket Sector. J Cleaner Product 112:3294-3305

Touboulic A, Chicksand D, Walker H (2014) Managing imbalanced supply chain relationships for sustainability: a power perspective. Decision Sci 45(4):577-619

Touboulic A, Walker H (2015) Love me, Love me not: a nuanced view on collaboration in sustainable supply chains. J Purchasing Supply Manag 21(3):178-191

Vafaeipour M, Zolfani SH, Varzandeh MHM, Derakhti A, Eshkalag MK (2014) Assessment of regions priority for implementation of solar projects in Iran: new application of a hybrid multicriteria decision making approach. Energy Conversion Manag 86:653-663

Keršuliene V, Zavadskas EK, Turskis Z (2010) Selection of rational dispute resolution method by applying new step-wise weight assessment ratio analysis (Swara). J Business Econ Manag 11(2):243-258

Wang C, Cheng Z, Yue XG, McAleer M (2020) Risk management of COVID-19 by universities in China. J Risk Financial Manag 13(2):36

Wang H, Jiang Z, Zhang H, Wang Y, Yang Y, Li Y (2019) An integrated MCDM approach considering demands-matching for reverse logistics. J Cleaner Product 208:199-210

Wankmüller C, Reiner G (2020) Coordination, cooperation and collaboration in relief supply chain management. J Business Econ 90(2):239-276

Wilhelm M, Blome C, Bhakoo V, Paulraj A (2016) Sustainability in multi-tier supply chains: understanding the double agency role of the first-tier supplier. J Operations Manag 41:42-60

Winter M, Knemeyer AM (2013) Exploring the integration of sustainability and supply chain management: current state and opportunities for future inquiry. Int J Phys Distrib Logistics Manag 43(1):18-38. https://doi.org/10.1108/09600031311293237

World Commission on Environment and Development (WCED) (1987) Report of the World Commission on Environment and Development: "Our Common Future". Med War, 4. https://doi.org/10. 1080/07488008808408783s 
World Trade Organization (2020) Trade set to plunge as COVID-19 pandemic upends global economy. Press Release, April 8. https:// www.wto.org/english/news_e/pres20_e/pr855_e.htm.

Wu KJ, Tseng ML, Chiu AS, Lim MK (2017) Achieving competitive advantage through supply chain agility under uncertainty: a novel multi-criteria decision-making structure. Int J Product Econ 190:96-107

Yawar SA, Seuring S (2017) Management of social issues in supply chains: a literature review exploring social issues, actions and performance outcomes. J Business Ethics 141(3):621-643
Zavadskas EK, Stević Ž, Tanackov I, Prentkovskis O (2018) A novel multicriteria approach-rough step-wise weight assessment ratio analysis method (R-SWARA) and its application in logistics. Stud Inform Control 27(1):97-106

Zolfani SH, Saparauskas J (2013) New application of SWARA method in prioritizing sustainability assessment indicators of energy system. Eng Econ 24(5):408-414

Publisher's note Springer Nature remains neutral with regard to jurisdictional claims in published maps and institutional affiliations. 